\title{
Genetic Gains With Selection for Yield and Soluble Solids Content in Cherry Tomato Hybrids
}

\author{
Felipe Barrera Sánchez \\ Departament of Agricultural Sciences, Universidad Nacional de Colombia, \\ Medellín, Colombia
}

Larissa Pereira Ribeiro and Mayara Fávero Cotrim
Departament of Agricultural Sciences, Universidade Federal de Mato
Grosso do Sul, Chapadão do Sul, Brazil

Carlos Antonio da Silva Junior

Departament of Geographic, Universidade do Estado do Mato Grosso, Sinop, Brazil

\section{Leonardo Lopes Bhering \\ Laboratory of Biometrics, Universidade Federal de Viçosa, Viçosa, Brazil}

\section{Paulo Eduardo Teodoro \\ Departament of Agricultural Sciences, Universidade Federal de Mato Grosso do Sul, Chapadão do Sul, Brazil}

Additional index words. tomato breeding, genetic advance, selection index

\begin{abstract}
This study aimed to estimate the predicted genetic gains with the simultaneous selection of yield traits and soluble solids content in cherry tomato hybrids. Twenty cherry tomato hybrids were evaluated in hydroponic cultivation in randomized block design with three replicates. The following traits were evaluated: number of clusters per plant, number of flowers per cluster, number of fruits per cluster, number of fruits per plant, fruit weight, fruit yield per plant, and total soluble solids content. The parameters of heritability, experimental CV, and genotypic CV were estimated. Subsequently, selection gains by direct selection and Mulamba and Mock index were estimated. Direct selection of cherry tomato hybrids for fruit yield and soluble solids content is inefficient because selection based on one of these traits will provide undesirable gains in the other. However, simultaneous selection for yield and taste quality is possible based on the Mulamba and Mock index because the methodology provided high selection gains for both yield and soluble solids content.
\end{abstract}

Cherry tomato (Lycopersicon esculentum Mill.) is fruit rich in various organic and inorganic compounds (Wang et al., 2018), and its popularity has grown due to increased consumption of minimally processed foods. It presents a composition different from other types of tomato, generally with higher levels of dry matter, soluble solids, titratable acidity, flavor index, $\beta$-carotene, ascorbic acid, total phenolics, and antioxidant activity (Figas et al., 2015).

Among the compounds, the total soluble solids content (TSS) stands out because the higher the TSS, the sweeter fruit flavor, and the higher ${ }^{\circ}$ Brix genotypes are preferred by consumers (Mitchell et al., 2019). In addition, to require the addition of less sugar

Received for publication 24 July 2019. Accepted for publication 14 Aug. 2019.

Published online 24 February 2020.

P.E.T. is the corresponding author. E-mail: eduteodoro@ hotmail.com.

This is an open access article distributed under the CC BY-NC-ND license (https://creativecommons. org/licenses/by-nc-nd/4.0/). et al., 2017; Ribeiro et al., 2016; Teodoro et al., 2014). To mitigate this problem, breeders have used selection indices as a strategy, making it possible to aggregate the multiple pieces of information contained in the experimental unit to combine several traits of economic interest (Cruz et al., 2012).

This study aimed to estimate the predicted genetic gains with the simultaneous selection of yield traits and soluble solids content in cherry tomato hybrids.

\section{Materials and Methods}

Obtaining and evaluating tomato hybrids. To obtain the hybrids, five cherry tomato lines (described in Supplemental Table 1) were crossed in the complete diallel scheme by method 1 of Griffing (1956). The parents were chosen for their agronomic and commercial interest traits. The crosses provided $20 \mathrm{~F}_{1}$ hybrids, which were evaluated in hydroponic cultivation at University of Caldas, located in the municipality of Manizales, Caldas, Colombia. The average altitude of the site is $2160 \mathrm{~m}$, with average temperature of $18{ }^{\circ} \mathrm{C}$ and relative humidity of $65 \%$.

The experiment was carried out in randomized block design with three replicates. At each replicate, four plants per treatment were evaluated. Sowing was carried out in nurseries containing 128 locules, using peat and rice husk as substrate in a $4: 1$ ratio. At $30 \mathrm{~d}$ after sowing, the seedlings were transplanted to gutters, planting 10 plants for each cross in case of loss. Irrigation was performed every $90 \mathrm{~min}$. Fertilization and irrigation were carried out with standard handling and supported by the tomato management under protected conditions (Jaramillo et al., 2007). Tutoring was performed at $26 \mathrm{~d}$ after transplantation to the final site using fine agricultural fiber. Harvesting began at $90 \mathrm{~d}$ after transplanting followed by sanitary pruning of the clusters responsible for filling the clusters that had already been collected and were diseased and old.

At maturation, the following traits related to yield were evaluated: number of clusters per plant (CP), number of flowers per cluster (FLC), number of fruits per cluster (FRC), and number of fruits per plant (FRP). At harvesting, the traits evaluated were fruit weight (FRW, g), evaluated by weighing harvested fruits and obtaining an average weight; fruit yield per plant (YIE, g), obtained by the sum of fruit weights per plant; and TSS content ( ${ }^{\circ}$ Brix), measured by using a refractometer in samples of fully mature fruits.

Statistical analysis. Initially, data were submitted to analysis of variance (ANOVA), according to the following statistical model:

$$
Y_{i j}=\mu+B_{j}+G_{i}+\varepsilon_{i j k},
$$
breeding programs is to select genotypes that simultaneously promote high yield and good taste quality. However, selection based on one or a few traits may result in unfavorable changes to other traits, due to negative genetic correlations among them (Naveen where $Y_{i j k}$ is the observation of the $i$-th genotype the $j$-th block; $\mu$ is the overall mean; $B_{j}$ is the effect of the $j$-th block; $G_{i}$ is the random effect of the $i$-th genotype; in the environment $j$; and $\varepsilon_{i j k}$ is the random error associated with the observation $Y_{i j}$. 
The genetic parameters broad-sense heritability $\left(\mathrm{h}^{2}\right)$, experimental coefficient of variation (Cv), and genotypic coefficient of variation (GCV) were estimated. Subsequently, the selection gains by direct selection and the Mulamba and Mock (1978) index were estimated, adopting a selection intensity of $20 \%$ and the $\mathrm{GCV}$ as economic weight for both methodologies. The Mulamba and Mock (1978) index initially ranks the genotypes for each trait by assigning higher absolute values to those with better performance. Finally, the values assigned to each trait are summed, obtaining the sum of the ranks, which indicates the genotypes classification (Cruz et al., 2012).

All statistical analyses were performed using the Genes software (Cruz, 2013).

\section{Results and Discussion}

ANOVA revealed a significant genotype effect $(P<0.01)$ for the traits FRC, FRP, FRW, and TSS, indicating the existence of genetic variability among hybrids for these traits (Table 1). Estimates of genetic parameters allow a better understanding of the genetic structure of the population and inference about their genetic variability, providing the ability to predict the genetic gains and possible success in the breeding program (Cruz et al., 2012). The high $\mathrm{h}^{2}$ estimates for FRC $(94.28 \%)$ and FRP $(86.87 \%)$ show that direct selection based on these traits is efficient because this parameter corresponds to the proportion of total variability that is genetic in nature (Falconer and Mackay, 1996), indicating that these traits are not greatly influenced by environment. Moderate estimates for TSS, YIE, and FLC, and particularly the low $\mathrm{h}^{2}$ estimates for CP and TSS, revealed a favorable influence of environment rather than genotype, and hence selection of superior genotypes for these traits would not be rewarding in early generations.

High estimates of GCV reveal a favorable situation for selection. With the exception of FRC and TSS, the other traits had high estimates of $\mathrm{GCV}$, especially the trait FRP, which had the highest estimate $(67.89 \%)$. Burton (1952) reported that the $\mathrm{GCV}$ associated with $\mathrm{h}^{2}$ estimates provide information on the expected gain with selection. In this sense, the selection based on FRP, which was associated with high $\mathrm{h}^{2}$ and GCV estimates, was shown to be promising for obtaining higher genetic gains. Similarly, high values of $\mathrm{GCV}$ and $h^{2}$ for FRP have already been reported in previous studies with tomato crop (Asati et al., 2008; Pradeepkumar et al., 2001).

The relationship between GCV and experimental $\mathrm{CV}(\mathrm{GCV} / \mathrm{CV})$ is another indicator of success with selection, with values close to or greater than unity demonstrating that trait selection is promising because the greater portion of the observed variability is due to genetic causes (Cruz et al., 2012). The traits FRC, FRP, FRW and TSS presented estimates of $\mathrm{GCV} / \mathrm{CV}$ higher than 1, highlighting FRP by presenting higher estimates of $\mathrm{GCV}$ and $\mathrm{h}^{2}$, and FRB by gathering the highest estimates of $\mathrm{GCV} / \mathrm{CV}$ and $\mathrm{h}^{2}$.

The main goal of cherry tomato breeding programs is to obtain genotypes with higher yield and fruit flavor quality (Sánchez et al., 2019). One of the traits related to the organoleptic quality of fruits is the soluble solids content measured in ${ }^{\circ}$ Brix, which is a fast and inexpensive field test that provides an approximation about how sweet the fruit is (Mitchell et al., 2019). Therefore, greater gains with the selection for TSS and YIE are desired. Table 2 presents the estimates of gains from direct selection and based on the Mulamba and Mock (1978) index. The means of the progenies selected by the Mulamba and Mock index for the evaluated traits are listed in Supplemental Table 2. It can be seen that the direct selection based on YIE and TSS traits was not successful. Although the direct selection on YIE provided a high selection gain $(369.31 \%)$, it resulted in undesirable gains for TSS (-1.19). Likewise, direct selection on TSS provided the highest selection gain for the trait $(6.66 \%)$; however, there was loss in selection for YIE $(-5.84)$.

The results obtained with direct selection were expected because this methodology is inefficient when it falls in correlated traits, making the selection of one trait result in changes in the behavior of another (Cruz et al., 2012; Naveen et al., 2017; Ribeiro et al., 2016; Teodoro et al., 2014). Therefore, direct selection of cherry tomato genotypes for YIE and TSS is not recommended because selection based on one of these traits will provide undesirable qualities in the other.

High GCV values and $\mathrm{h}^{2}$ associated with higher gains also indicate that additive gene effects regulate trait inheritance (Narayan et al., 1996), and therefore selection may be more effective. This corroborates the results obtained by direct selection on FRC and FRP, which resulted in high gains for these traits associated with satisfactory gains for YIE and TSS. Therefore, direct selection on YIE and TSS is inefficient, whereas direct selection on FRC and FRP appear to be promising to obtain indirect gains for fruit yield and soluble solids content.

The Mulamba and Mock (1978) index provided more satisfactory selection gains, resulting in simultaneous gains for YIE and

Table 1 . Summary of the analysis of variance and genetic parameters assessed in 20 cherry tomato hybrids.

\begin{tabular}{|c|c|c|c|c|c|c|c|c|}
\hline \multirow[b]{2}{*}{ Source of variation } & \multirow[b]{2}{*}{$\mathrm{df}$} & \multicolumn{7}{|c|}{ Mean squares } \\
\hline & & $\mathrm{CP}$ & FLC & FRC & FRP & FRW & YIE & TSS \\
\hline Genotype & 19 & $5.23 \mathrm{NS}$ & $12.89 \mathrm{NS}$ & $1,789.04 *$ & $770.25^{*}$ & $21.47 *$ & $0.06 \mathrm{NS}$ & $0.85 *$ \\
\hline GCV & & 15.32 & 18.57 & 2.36 & 67.89 & 36.97 & 35.53 & 6.79 \\
\hline $\mathrm{GCV} / \mathrm{CV}$ & & 0.69 & 0.75 & 2.37 & 1.50 & 1.53 & 0.77 & 1.09 \\
\hline
\end{tabular}

$\mathrm{df}=$ degrees of freedom; $\mathrm{h}^{2}=$ heritability; $\mathrm{GCV}=$ genotypic coefficient of variation; $\mathrm{CV}=$ experimental coefficient of variation; $\mathrm{CP}=$ number of clusters per plant; $\mathrm{FLC}=$ number of flowers per cluster; $\mathrm{FRC}=$ number of fruits per cluster; $\mathrm{FRP}=$ number of fruits per plant; $\mathrm{FRW}=$ fruit weight $(\mathrm{g}) ; \mathrm{YIE}=$ fruit yield per plant $(\mathrm{g})$; TSS $=$ total soluble solids content $\left({ }^{\circ}\right.$ Brix $)$.

Ns, *Nonsignificant or significant at the $1 \%$ probability level by $F$ test, respectively.

Table 2. Estimates of percentage gains with selection (GS\%) based on direct selection and Mulamba and Mock (1978) index, assessed in 20 cherry tomato hybrids.

\begin{tabular}{|c|c|c|c|c|c|c|c|}
\hline \multirow[b]{2}{*}{ Method } & \multicolumn{7}{|c|}{ GS\% } \\
\hline & $\mathrm{CP}$ & FLC & FRC & FRP & FRW & YIE & $\overline{\mathrm{TSS}}$ \\
\hline \multicolumn{8}{|l|}{ Direct Selection on } \\
\hline $\mathrm{CP}$ & 16.87 & -11.29 & -77.98 & 49.51 & -5.69 & -4.85 & -2.04 \\
\hline FRC & -2.89 & 19.06 & 135.40 & -46.79 & 5.15 & 25.84 & 2.73 \\
\hline FRP & 12.79 & -0.58 & -72.46 & 97.2 & -3.03 & 13.96 & 2.48 \\
\hline FRW & -4.45 & 1.81 & -1.50 & -14.61 & 46.81 & 25.84 & -0.06 \\
\hline YIE & -5.43 & 14.64 & 58.90 & -2.60 & 34.87 & 369.21 & -1.19 \\
\hline
\end{tabular}

$\mathrm{CP}=$ number of clusters per plant; $\mathrm{FLC}=$ number of flowers per cluster; $\mathrm{FRC}=$ number of fruits per cluster; $\mathrm{FRP}=$ number of fruits per plant; $\mathrm{FRW}=$ fruit weight $(\mathrm{g})$; YIE $=$ fruit yield per plant $(\mathrm{g})$; TSS $=$ total soluble solids content $\left({ }^{\circ} \mathrm{Brix}\right)$. 
TSS. Therefore, the Mulamba and Mock index is the most recommended for the selection of cherry tomato genotypes with high yield and taste quality.

\section{Conclusion}

Direct selection of cherry tomato genotypes for fruit yield and soluble solids content is inefficient and detrimental to the breeding process because selection based on one of these traits will provide undesirable gains in the other.

Simultaneous selection of genotypes for yield and quality of fruit taste is possible based on the Mulamba and Mock index because this methodology provided high selection gains for both yield and soluble solids content in cherry tomato fruits.

\section{Literature Cited}

Araújo, J.C., S.F.P. Telhado, R.H. Sakai, C.A.S. Ledo, and P.C.T. Melo. 2016. Univariate and multivariate procedures for agronomic evaluation of organically grown tomato cultivars. Hort. Bras. 34:374-380.

Asati, B.S., N. Rai, and A.K. Singh. 2008. Genetic parameters study for yield and quality traits in tomato. Asian J. Hort. 3(2):222-225.

Baxter, C.J., F. Carrari, A. Bauke, S. Overy, S.A. Hill, P.W. Quick, A.R. Fernie, and L.J. Sweetlove.
2005. Fruit carbohydrate metabolism in an introgression line of tomato with increased fruit soluble solids. Plant Cell Physiol. 46: 425-437.

Burton, G.W. 1952. Quantitative inheritance in grass. Proc. 6th Int. Grassland Congress 1:277283.

Cruz, C.D. 2013. GENES - a software package for analysis in experimental statistics and quantitative genetics. Acta Sci. Agron. 35:2271-2276.

Cruz, C.D., A.J. Regazzi, and P.C.S. Carneiro. 2012. Modelos biométricos aplicados ao melhoramento genético. UFV, Viçosa, Brazil.

Falconer, D. and T. Mackay. 1996. Introduction to quantitative genetics. Longman, Harlow, UK.

Figas, M.R., J. Prohens, M.D. Raigón, A. Fita, M.D. García-Martínez, C. Casanova, D. Borràs, M. Plazas, I. Andújar, and S. Soler. 2015. Characterization of composition traits related to organoleptic and functional quality for the differentiation, selection and enhancement of local varieties of tomato from different cultivar groups. Food Chem. 187:517-524.

Griffing, B. 1956. Concept of general and specific combining ability in relation to diallel crossing system. Aust. J. Biol. Sci. 90:463-492.

Jaramillo, J., V.P. Rodríguez, M. Guzmán, M Zapata, and T. Rengifo. 2007. Buenas Prácticas Agrícolas-BPA en la producción de tomate bajo condiciones protegidas. Corpoica, FAO, Medellín, Colombia.

Mitchell, B.A., M.E. Uchanski, and A. Elliott. 2019 Fruit cluster pruning of tomato in an organic high-tunnel system. HortScience 54:311-316.
Mulamba, N.N. and J.J. Mock. 1978. Improvement of yield potential of the Eto Blanco maize (Zea mays L.) population by breeding for plant traits. Egypt. J. Genet. Cytol. 7:40-51.

Narayan, R., S.P. Singh, D.K. Sharma, and K.B. Rastogi. 1996. Genetic variability and selection parameters in bottle gourd. Indian J. Hort. 53:53-58.

Naveen, B.L., P. Saidaiah, K. Ravinderreddy, and A. Geetha. 2017. Correlation and path coefficient analysis of yield and yield attributes in tomato (Solanum lycopersicum L.). J. Pharm.Phyt. 6:665-669.

Pradeepkumar, T., D. Bastian, N.V. Radhakrishnan, and K.C. Aipe. 2001. Genetic variation in tomato for yield and resistance to bacterial wilt. J. Trop. Agr. 39:157-158.

Ribeiro, L.P., P.E. Teodoro, C.C.G. Correa, E.P. Oliveira, F.A. Silva, and F.E. Torres. 2016. Correlations and genetic parameters in maize hybrids. Biosci. J. 32:48-54.

Sánchez, F.B., L.P. Ribeiro, E.V. Rodrigues, L.L. Bhering, and P.E. Teodoro. 2019. Correlations and path analysis in cherry tomato genotypes. Funct. Plant Breed. J. 1:1-7.

Teodoro, P.E., C.A. Silva, Junior., C.C. Corrêa, L.P. Ribeiro, E.P. Oliveira, M.F. Lima, and F.E. Torres. 2014. Path analysis and correlation of two genetic classes of maize (Zea mays L.) J. Agron. 13:23-28

Wang, S., Z. Chu, R. Jia, F. Dan, X. Shen, Y. Li, and X. Ding. 2018. Slmyb12 Regulates flavonol synthesis in three different cherry tomato varieties. Sci. Rpt. 8:1582. 
Supplemental Table 1. Code, origin, description, and characteristics of the five parents used for obtaining the 20 cherry tomato hybrids.

\begin{tabular}{|c|c|c|c|}
\hline Parental code & Origin & Description & Characteristics \\
\hline IAC $1688^{z}$ & Brazil & Cherry tomato 'Lili' & High yield per plant and high number of flowers per cluster \\
\hline IAC $420^{z}$ & Brazil & Cherry tomato & $\begin{array}{l}\text { High soluble solids content, high number of clusters per plant, } \\
\text { high number of fruits per cluster and high average fruit weight }\end{array}$ \\
\hline LA3158 & Mexico & S. pimpinelifollium & $\begin{array}{l}\text { High soluble solids content, high number of clusters per plant } \\
\text { and low yield per plant }\end{array}$ \\
\hline
\end{tabular}

${ }^{\mathrm{z}}$ Introductions from the Agronomic Institute of Campinas, Brazil

${ }^{\mathrm{y}}$ Introductions from the Tomato Genetics Resources Center (TGRC) of the University of California, Davis.

Supplemental Table 2. Means of the top hybrids selected by the Mulamba and Mock (1978) index for number of clusters per plant (CP), number of flowers per cluster (FLC), number of fruits per cluster (FRC), number of fruits per plant (FRP), fruit weight (FRW, g), fruit yield per plant (YIE, g), and total soluble solids content (TSS, ${ }^{\circ}$ Brix).

\begin{tabular}{lccccccr}
\hline Hybrid & CP & FLC & FRC & FRP & FRW & YIE & TSS \\
\hline IAC426 × IAC1688 & 6.42 & 11.25 & 69.25 & 10.42 & 8.02 & 0.52 & 7.11 \\
IAC1688 $\times$ LA 1480 & 6.75 & 11.87 & 7.95 & 57.5 & 7.67 & 0.53 & 7.45 \\
IAC426 × IAC420 & 5.83 & 12.33 & 60.58 & 10.25 & 8.93 & 0.56 & 6.79 \\
IAC1688 $\times$ LA3158 & 6.00 & 12.83 & 66.33 & 10.92 & 7.36 & 0.48 & 7.58 \\
\hline
\end{tabular}

